Research Paper

\title{
Long-Term Outcome of Inflammatory Breast Cancer Compared to Non-Inflammatory Breast Cancer in the Setting of High-Dose Chemotherapy with Autologous Hematopoietic Cell Transplantation
}

\author{
Yee Chung Cheng1 ${ }^{1 凶}$, Yushu Shi ${ }^{1}$, Mei-Jie Zhang2,3, Ruta Brazauskas², Michael T. Hemmer², Michael R.
} Bishop 4 , Yago Nieto ${ }^{5}$ Edward Stadtmauer6, Lois Ayash7, Robert Peter Gale ${ }^{8}$, Hillard Lazarus ${ }^{9}$, Leona Holmberg10, Michael Lill11, Richard F. Olsson12, 13, Baldeep Mona Wirk14, Mukta Arora15, Parameswaran Hari $^{2}$, Naoto Ueno ${ }^{5}$

1. Medical College of Wisconsin, Milwaukee, WI;

2. CIBMTR(Center for International Blood and Marrow Transplant Research), Department of Medicine, Medical College of Wisconsin, Milwaukee, Wisconsin;

. Division of Biostatistics, Institute for Health and Society, Medical College of Wisconsin, Milwaukee, WI;

4. University of Chicago Hospitals, Chicago, IL;

5. Department of Stem Cell Transplantation and Cellular Therapy, The University of Texas M.D. Anderson Cancer Center, Houston, TX;

6. Abramson Cancer Center University of Pennsylvania Medical Center, Philadelphia, PA:

7. Karmanos Cancer Institute, Detroit, MI; Division of Hematology, Oncology, Transplantation, Department of Medicine, University of Minnesota Medical Center, Minneapolis, Minnesota;

8. Hematology Research Centre, Division of Experimental Medicine, Department of Medicine, Imperial College London, London, United Kingdom;

9. Seidman Cancer Center, University Hospitals Case Medical Center, Cleveland, $\mathrm{OH}$;

10. Fred Hutchinson Cancer Research Center, Seattle, WA;

11. Cedars-Sinai Medical Center, Los Angeles, CA;

12. Division of Therapeutic Immunology, Department of Laboratory Medicine, Karolinska Institutet, Stockholm, Sweden

13. Centre for Clinical Research Sormland, Uppsala University, Uppsala, Sweden;

14. Division of Bone Marrow Transplant, Seattle Cancer Care Alliance, Seattle, WA

15. Division of Hematology, Oncology, and Transplantation, Department of Medicine, University of Minnesota Medical Center, Minneapolis, MN

$\square$ Corresponding author: Yee Chung Cheng, ycheng@mcw.edu.

(c) Ivyspring International Publisher. This is an open access article distributed under the terms of the Creative Commons Attribution (CC BY-NC) license (https://creativecommons.org/licenses/by-nc/4.0/). See http://ivyspring.com/terms for full terms and conditions.

Received: 2016.07.16; Accepted: 2016.12.03; Published: 2017.03.25

\begin{abstract}
Introduction: Inflammatory breast cancer (IBC) is a rare aggressive form of breast cancer. It is well known that the long-term survival and progression-free survival of IBC are worse than that of non-IBC. We report the long term outcomes of patients with IBC and non-IBC who had undergone high-dose chemotherapy (HDC) with autologous hematopoietic cell transplantation (AHCT).

Methods: All 3387 patients with IBC or non-IBC who underwent HDC with AHCT between 1990-2002 and registered with CIBMTR were included in this analysis. Transplant-related mortality (TRM), disease relapse/progression, progression-free survival (PFS) and overall survival (OS) were compared between the two cohorts. Multivariate Cox regression model was used to determine the independent impact of stage on outcomes.

Results: 527 patients with IBC and 2,860 patients with non-IBC were included; the median age at transplantation (47 vs 46 years old) and median follow-up period in the 2 groups (167 vs 168 months) were similar. The most common conditioning regimen was cyclophosphamide and carboplatin based in both groups (54\% in IBC and $50 \%$ in non-IBC). AHCT was well tolerated in both groups. TRM was similar in both groups (one year TRM was $2 \%$ for IBC and $3 \%$ for non-IBC, $p=0.16$ ). The most common cause of death was disease progression or relapse ( $81 \%$ in IBC and $75 \%$ in non-IBC). The median survival for both IBC and non-IBC was the same at 40 months. The PFS at 10 years was $27 \%$ (95\% Cl: $23-31 \%)$ for IBC and $24 \%(95 \% \mathrm{Cl}: 22-26 \%)$ for non-IBC $(p=0.21)$, and the OS at 10 years was $31 \%(95 \% \mathrm{Cl}$ : $27-35 \%)$ for IBC and $28 \%(95 \% \mathrm{Cl}: 26-30 \%)$ for non-IBC $(p=0.16)$. In univariate analysis, patients with stage III IBC and no active diseases at transplantation had lower PFS and OS than that in non-IBC. In multivariate analysis, controlling for age, disease status at AHCT, hormonal receptor status, time from
\end{abstract}


diagnosis to AHCT, and performance status at AHCT, patients with stage III IBC had higher mortality (HR 1.16, 95\% Cl: 1-1.34, $p=0.0459$ ), worse PFS (HR: 1.17, 95\% Cl: 1.01-1.36, $p=0.0339$ ) and higher risk of disease relapse/progression (HR: 1.24, 95\% Cl: 1.06-1.45, $p=0.0082$ ) as compared to stage III non-IBC. Amongst all patients a higher stage disease was associated with worse PFS, OS and disease relapse/progression.

Conclusions: Long-term outcomes of stage III IBC patients who underwent AHCT were poorer than that in non-IBC patients confirming that the poor prognosis of IBC even in the setting of HDC with AHCT.

Key words: Inflammatory Breast Cancer, Hematopoietic Cell Transplantation

\section{Introduction}

Inflammatory breast cancer (IBC) is a rare type of invasive breast cancer that occurs in only about $2-5 \%$ of all breast cancer cases. ${ }^{1}$ However, it is one of the most aggressive forms of invasive breast cancer. It frequently presents with regional lymph node involvement and is followed by rapid disease progression to distant involvement from micrometastasis in the natural course of disease. With locoregional treatment only, long-term survival is less than $5 \% .^{2}$ With the addition of systemic cytotoxic chemotherapy together with locoregional treatment, the long term survival has improved significantly but still resides between $30-50 \% .^{2}$ IBC, being a chemo-sensitive disease, the standard main force of treatment is systemic cytotoxic chemotherapy. Compared to non-IBC, a previous study has found a survival hazard ratio (HR) of 1.43 for IBC using standard dose systemic cytotoxic chemotherapy. ${ }^{3}$ One area of research in improving the IBC outcome was the potential use of high-dose chemotherapy (HDC) with autologous hematopoietic stem-cell transplantation (AHCT).

Multiple phase II studies of HDC with AHCT have been conducted in IBC which suggested a survival benefit in this aggressive locally advanced breast cancer compared to historical data of non-transplant approach. 4-16 In 1997, Antman et al. published the first report of HDC with AHCT for breast cancer in North America using data in the Autologous Blood and Marrow Transplant Registry (ABMTR). ${ }^{17}$ Between January 1, 1989 and June 30, 1995, a total of 260 non-metastatic IBC patients receiving $\mathrm{HDC}$ with $\mathrm{AHCT}$ for breast cancer were reported to ABMTR. The 3-year Kaplan-Meier estimates of progression-free survival (PFS) were $42 \%$ (95\% confidence interval [CI] of 31-53\%) and the 3 -year Kaplan-Meier estimates of overall survival (OS) were $52 \%$ (95\% CI of $40-64 \%$ ).

In 2003, Pedrazzoli et al. reported the data of European Group for Blood and Marrow Transplantation registry between 1990 and 1999.18 A total of 921 patients with IBC underwent HDC with AHCT. Five years PFS was reported as $42 \%$ and 5 years OS was $53 \%$.

However, these data were all reported decades ago. Therefore, it is worth studying the outcome of IBC patients and that of non-IBC patients who underwent HDC with AHCT again using the current global blood and marrow transplant registry data. Our primary objective was to compare the long-term outcomes of HDC with AHCT in IBC with that of non-IBC patients receiving HDC with AHCT.

\section{Methods}

The Center for International Blood \& Marrow Transplant Research (CIBMTR), is a research affiliation of the International Bone Marrow Transplant Registry (IBMTR), ABMTR, and the National Marrow Donor Program (NMDP). The CIBMTR comprises a voluntary working group of more than 450 transplantation centers worldwide that contribute detailed data on consecutive allogeneic and autologous hematopoietic cell transplantation to a Statistical Center at the Medical College of Wisconsin in Milwaukee and the NMDP Coordinating Center in Minneapolis. Participating centers are required to report all transplants consecutively. Patients are followed longitudinally. Computerized checks for discrepancies, physicians' review of submitted data, and on-site audits of participating centers ensure data quality. Observational studies conducted by the CIBMTR are performed in compliance with all applicable federal regulations pertaining to the protection of human research participants. Protected Health Information used in such research is collected and maintained in CIBMTR's capacity as a Public Health Authority under the HIPAA Privacy Rule.

\section{Patients}

All patients who underwent HDC with AHCT for IBC or non-IBC between 1990 and 2002 were eligible for the study. Since follow-up information regarding long-term survival and secondary malignancies was required, patients from centers with a follow-up completeness index (ratio of total observed to potential person-time of follow-up) of $<$ 
$80 \%$ at 10 years after transplantation were excluded $(n=2423$, from 98 centers). The final study population consisted of 3387 patients from 91 centers. Pathology and physician reports of second cancers were reviewed centrally, and if necessary, tumors were reclassified.

\section{Statistical Methods}

The objectives of this study were to compare the long-term outcomes between the IBC and non-IBC cohorts. The primary outcomes were PFS and OS. Secondary outcomes included disease relapse/progression, transplant related mortality (TRM) and cumulative incidence of secondary malignancy. Tables of patient-, disease-, treatmentand transplant-related characteristics were described using standard techniques. Continuous variables were reported as medians with ranges, while categorical variables were reported as absolute numbers and percent of total patients. The diagnosis of IBC is based on criteria described in AJCC cancer staging manual and the stage is at least stage IIIB. When the breast cancer presented de novo with distant metastasis, it was recorded as stage IV. TRM was defined as death in continued remission; patients were censored at relapse/progression, or for those in continuous remission, at last follow-up. For PFS, patients were considered treatment failures at the time of relapse or disease progression or death from any cause; patients alive were censored at the last follow-up evaluation. TRM, relapse/disease progression and secondary malignancy were estimated as cumulative incidences, taking into account competing risks. Probability of PFS was calculated using the Kaplan-Meier estimator with variance estimated by the Greenwood formula. Comparison of survival curves was done using the log-rank test. In multivariate analysis, a stepwise selection procedure was performed using the proportional hazards model.

\section{Results}

\section{Patient Characteristics}

Our study population included 527 patients with IBC and 2,860 patients with non-IBC (Table 1). Among them, 442 patients $(84 \%)$ with IBC had no de novo distant metastatic disease (stage III) and 2,302 patients $(80 \%)$ with non-IBC had high risk stage II/III disease at initial presentation. The median age at transplantation (47 vs 46 years old) and median follow-up period in the 2 groups (167 vs 168 months) were similar. About half of the patients were premenopausal ( $53 \%$ vs $50 \%$ ). Majority ( $84 \%$ vs $80 \%$ in IBC and non-IBC groups, respectively) had a good performance status (KPS $\geq 90 \%$ ) at transplant. At the time of transplantation, 346 patients $(66 \%)$ with IBC and 1,425 patients (50\%) with non-IBC had no evidence of active disease. Among the 85 patients (16\%) with IBC and 558 patients $(20 \%)$ with non-IBC who had stage IV disease, a majority of them had only one metastatic site (49 in IBC and 324 in non-IBC) with skin (other than the ipsilateral breast) being the most common metastatic site in IBC and bone in non-IBC. One hundred eighty-six patients $(35 \%)$ with IBC and 830 patients $(29 \%)$ with non-IBC were hormone receptor negative. HER2 receptor information was not available. Three hundred and four patients (58\%) with IBC and 293 patients (10\%) with non-IBC received neoadjuvant chemotherapy but only 55 and 64 patients respectively had complete response to neoadjuvant treatment. Majority of patients had surgery (90\% vs 95\%) and adjuvant chemotherapy $(60 \%$ vs $67 \%)$ as part of their initial treatment before transplant. Single AHCT (versus tandem AHCT) was the common strategy in both groups (93\%). The most commonly used conditioning regimen was cyclophosphamide, carboplatin, and others in both groups (54\% in IBC and 50\% in non-IBC). Majority used peripheral blood cells as the graft source $(91 \%$ vs $88 \%$ ). Median time from diagnosis to transplant was also similar in 2 groups $(7$ months in IBC and 10 months in non-IBC). With median follow up of 14 years, 10 patients in IBC and 42 patients in non-IBC developed second malignancy (Table 1). Overall, the cumulative incidence of a second primary malignancy in the entire cohort at 10 years post-transplant was 3\% (95\% CI: 2 to $4 \%$ ) with 3\% in the IBC group (95\% CI: 2 to $4 \%$ ) versus $2 \%$ ( $95 \% \mathrm{CI}: 0$ to $5 \%$ ) in the non-IBC group. The most common cause of death was disease progression (81\% in IBC and $75 \%$ in non-IBC) (Table 2).

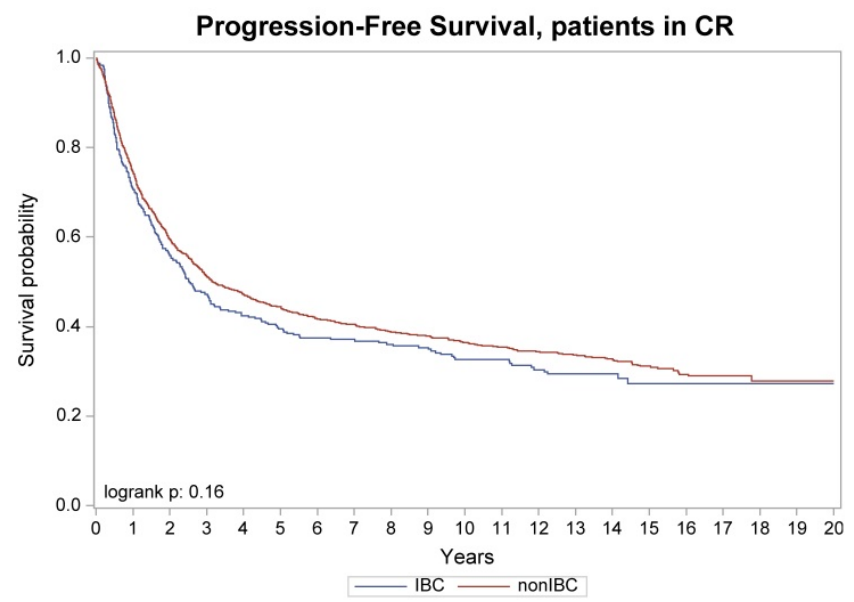

Figure 1. Progression-free survival, patients with no active diseases at transplant 
Table 1. Characteristics of adult patients who underwent first autologous transplant for IBC and non-IBC from 1990-2002, as reported to the CIBMTR.

\begin{tabular}{|c|c|c|}
\hline Characteristics of patients: & IBC & Non-IBC \\
\hline Number of patients & 527 & 2860 \\
\hline Number of transplant centers & 68 & 89 \\
\hline Median (range) follow-up in months & $167(6-266)$ & $168(5-261)$ \\
\hline \multicolumn{3}{|l|}{ Patient-related } \\
\hline Median (range) age at transplant in years & $47(21-66)$ & $46(22-70)$ \\
\hline \multicolumn{3}{|l|}{ Menopausal status } \\
\hline Premenopausal & $278(53)$ & $1427(50)$ \\
\hline Postmenopausal & $170(32)$ & $615(21)$ \\
\hline Missing & $79(15)$ & $818(29)$ \\
\hline \multicolumn{3}{|l|}{ Karnofsky score prior to transplant } \\
\hline$<90 \%$ & $81(16)$ & $573(20)$ \\
\hline$\geq 90 \%$ & $446(84)$ & $2287(80)$ \\
\hline \multicolumn{3}{|l|}{ Disease-related } \\
\hline \multicolumn{3}{|l|}{$\overline{\text { Stage of breast cancer }}$} \\
\hline Stage II & 0 & $1612(56)$ \\
\hline Stage III & $442(84)$ & $690(24)$ \\
\hline Stage IV & $85(16)$ & $558(20)$ \\
\hline \multicolumn{3}{|l|}{ Disease status at time of transplant } \\
\hline Complete response & $346(66)$ & $1425(50)$ \\
\hline Partial response & $80(15)$ & $521(18)$ \\
\hline Stable & $44(8)$ & $234(8)$ \\
\hline Progressive disease & $18(4)$ & $112(4)$ \\
\hline Missing & $39(7)$ & $568(20)$ \\
\hline \multicolumn{3}{|l|}{ Sites of metastases } \\
\hline Skin & 32 & 14 \\
\hline Bone & 16 & 206 \\
\hline Bone marrow & 0 & 13 \\
\hline Lymph node & 12 & 122 \\
\hline Liver & 11 & 91 \\
\hline Lung & 2 & 22 \\
\hline CNS & 0 & 3 \\
\hline Others & 9 & 17 \\
\hline Missing & 12 & 154 \\
\hline Characteristics of patients (continued): & IBC & Non-IBC \\
\hline Number of patients & 527 & 2860 \\
\hline \multicolumn{3}{|l|}{ Number of metastases sites } \\
\hline 1 & 49 & 324 \\
\hline 2 & 24 & 114 \\
\hline 3 & 3 & 29 \\
\hline 4 & 0 & 7 \\
\hline 5 & 2 & 1 \\
\hline \multicolumn{3}{|l|}{ Estrogen / Progesterone receptor status } \\
\hline$+/+$ & $150(28)$ & $1216(43)$ \\
\hline$+/-$ or $-/+$ & $83(16)$ & $453(16)$ \\
\hline$-/-$ & $186(35)$ & $830(29)$ \\
\hline Borderline & $11(2)$ & $54(2)$ \\
\hline Missing & $97(19)$ & $307(10)$ \\
\hline \multicolumn{3}{|l|}{ Treatment-related } \\
\hline \multicolumn{3}{|l|}{ Type of neoadjuvant treatment } \\
\hline No neoadjuvant treatment given & $201(38)$ & $2492(87)$ \\
\hline Chemotherapy \pm others & $304(58)$ & $293(10)$ \\
\hline Missing & $22(4)$ & $75(3)$ \\
\hline \multicolumn{3}{|l|}{ Response to neoadjuvant treatment } \\
\hline Complete response & $55(10)$ & $64(2)$ \\
\hline Partial response & $183(35)$ & $156(5)$ \\
\hline Stable and/or Progressive disease & $41(8)$ & $38(1)$ \\
\hline Missing & $47(9)$ & $110(4)$ \\
\hline \multicolumn{3}{|l|}{ Surgery part of initial management } \\
\hline Yes & $475(90)$ & $2729(95)$ \\
\hline No & $52(10)$ & $131(5)$ \\
\hline Type of adjuvant treatment & & \\
\hline No adjuvant treatment given & $156(30)$ & $303(11)$ \\
\hline Chemotherapy \pm others & $321(60)$ & $1916(67)$ \\
\hline Hormone therapy and/or Radiation & $24(5)$ & $88(3)$ \\
\hline Missing & $26(5)$ & $553(19)$ \\
\hline$\underline{\text { Transplant-related }}$ & & \\
\hline Type of autologous transplant & & \\
\hline Single & $489(93)$ & $2647(93)$ \\
\hline Tandem & $32(6)$ & $162(5)$ \\
\hline
\end{tabular}

\begin{tabular}{|c|c|c|}
\hline Characteristics of patients: & IBC & Non-IBC \\
\hline Unknown & $6(1)$ & $51(2)$ \\
\hline \multicolumn{3}{|l|}{ Conditioning regimen } \\
\hline $\mathrm{CY}+\mathrm{CARB}+$ others & $285(54)$ & $1430(50)$ \\
\hline $\mathrm{CY}+\mathrm{CISP}+$ others & $38(7)$ & $255(9)$ \\
\hline $\mathrm{CY}+\mathrm{THIO}+$ others & $124(24)$ & $608(21)$ \\
\hline $\mathrm{CY}+$ others & $17(3)$ & $160(6)$ \\
\hline CARB + others & $46(9)$ & $212(7)$ \\
\hline LPAM + others & $7(1)$ & $80(3)$ \\
\hline Others & $10(2)$ & $115(4)$ \\
\hline \multicolumn{3}{|l|}{ Graft source } \\
\hline BM & $50(9)$ & 327 (12) \\
\hline PBSC & $430(82)$ & $2185(76)$ \\
\hline $\mathrm{PBSC}+\mathrm{BM}$ & $47(9)$ & $348(12)$ \\
\hline $\begin{array}{l}\text { Median (range) time from diagnosis to } \\
\text { transplant in months }\end{array}$ & $7(1-127)$ & $10(<1-200)$ \\
\hline \multicolumn{3}{|l|}{ Time from diagnosis to transplant in months } \\
\hline$<3$ & $10(2)$ & $16(<1)$ \\
\hline $3-6$ & $163(31)$ & $697(24)$ \\
\hline $6-12$ & $248(47)$ & $837(29)$ \\
\hline$>12$ & $106(20)$ & $1310(46)$ \\
\hline \multicolumn{3}{|l|}{ Second malignancy } \\
\hline Total cases & 10 & 42 \\
\hline MDS & $2(20)$ & $6(14)$ \\
\hline AML & $1(10)$ & $4(10)$ \\
\hline Hodgkin Lymphoma & $1(10)$ & 0 \\
\hline Non-Hodgkin lymphoma & 0 & $1(2)$ \\
\hline Lung cancer & $2(20)$ & $2(5)$ \\
\hline Skin cancer & $1(10)$ & $11(26)$ \\
\hline Endometrial/Cervical cancer & $1(10)$ & $3(7)$ \\
\hline Ovarian cancer & 0 & $3(7)$ \\
\hline Thyroid cancer & 0 & $1(2)$ \\
\hline Head and neck cancer & $1(10)$ & $6(14)$ \\
\hline Colon cancer & 0 & $2(5)$ \\
\hline Leiomyosarcoma & 0 & $1(2)$ \\
\hline Adenocarcinoma of unknown primary & $1(10)$ & $2(5)$ \\
\hline
\end{tabular}

Table 2. Causes of death

\begin{tabular}{lll}
\hline Cause of death & IBC & Non-IBC \\
\hline Number evaluable & 382 & 2131 \\
Persistent disease & $23(6)$ & $189(9)$ \\
Relapse/Progression & $308(81)$ & $1595(75)$ \\
Second malignancy & $4(1)$ & $18(1)$ \\
GVHD & 0 & $2(<1)$ \\
IPS & $3(1)$ & $14(1)$ \\
Infection & $1(<1)$ & $24(1)$ \\
Organ failure & $5(1)$ & $55(3)$ \\
Others a & $3(1)$ & $34(2)$ \\
Unknown & $35(9)$ & $200(9)$ \\
\hline a IBC: Complications related to CVA (n=1), Shock (n=1), Hepatorenal syndrome \\
(n=1). \\
Non-IBC: Graft rejection (n=9), Hemorrhage (n=5), Other HCT-related cause $(\mathrm{n}=4)$, \\
Accidental death (n=3), Pulmonary ( $\mathrm{n}=2)$, Prior malignancy $(\mathrm{n}=2)$. \\
Abbreviations: IPS: Idiopathic pneumonia syndrome.
\end{tabular}

\section{Outcomes}

In univariate analysis the cumulative incidence of TRM at 1 year was $2 \%$ (95\% CI:1-4\%) for IBC and $3 \%(95 \%$ CI:3-4\%) for non-IBC $(p=0.16)$ (Table 3). The cumulative incidence of relapse/progression at 1 year was 39\% (95\% CI:35-43\%) for IBC and 38\% (95\% CI:36-40\%) for non-IBC ( $p=0.79)$, but at 10 years was $67 \% \quad(95 \%$ CI:63-71\%) for IBC and $69 \% \quad(95 \%$ CI:68-71\%) for non-IBC $(p=0.36)$. The median survival for IBC was 40 months which was the same as that of the non-IBC. The probability of PFS at 1 year was $59 \%$ 
(95\% CI:54-63\%) for IBC and 58\% (95\% CI:57-60\%) for non-IBC $(p=0.86)$, but at 10 years was $27 \%(95 \% \mathrm{CI}$ : $23-31 \%)$ for IBC and $24 \%$ (95\% CI: $22-26 \%)$ for non-IBC $(p=0.21)$, and the probability of OS at 1 year was $82 \%$ (95\% CI:79-85\%) for IBC and $80 \%(95 \%$ CI:79-82\%) for non-IBC ( $p=0.41)$, but at 10 years was $31 \%(95 \%$ CI: $27-35 \%)$ for IBC and $28 \%$ (95\% CI: $26-30 \%)$ for non-IBC $(p=0.16)$.

No difference was seen in TRM, 1-year and 10-year relapse/progression, 1-year and 10-year PFS, and 1-year and 10-year OS between stage III IBC $(\mathrm{n}=442)$ and stage II/III non-IBC $(\mathrm{n}=2,302)$ (Table 3). No difference was also seen in TRM, relapse/progression, PFS and OS between IBC $(n=346)$ and non-IBC $(n=1,425)$ patients who had no active disease at transplantation (Figure 1 and 2). However, among the subgroup of patients with stage III IBC $(n=304)$ or stage II/III non-IBC $(n=417)$ at presentation and had no active disease at transplantation (Table 3), an univariate analysis showed that the IBC patients had worse outcomes than did non-IBC patients in terms of 1-year relapse rate $(26 \%$ vs $18 \%, p=0.01), 10$-year relapse rate $(60 \%$ vs $50 \%, p=0.01), 10$-year PFS rate ( $34 \%$ vs $42 \%, p=0.05)$, and 10 -year OS rate ( $37 \%$ vs $45 \%, p=0.03$ ) (Figure 3 ).

In multivariate analysis, controlling for age, disease status at AHCT, hormonal receptor status, time from diagnosis to AHCT, and Karnofsky performance score (KPS) at AHCT, amongst patients with stage III IBC had higher mortality (HR 1.16, 95\% CI: 1-1.34, $p=0.0459$ ), worse PFS (HR: $1.17,95 \% \mathrm{CI}$ : 1.01-1.36, $p=0.0339$ ) and higher risk of disease relapse/progression (HR: 1.24, 95\% CI: 1.06-1.45, $p=$ 0.0082 ) as compared to non-IBC (Tables 4). Amongst all patients a higher stage disease was associated with worse survival outcomes (PFS and OS).

\section{Discussion}

Our study showed that on univariate analysis, the short term (1-year) and long term (10-year) outcomes of HDC with AHCT in IBC were similar to that in non-IBC. These similar results were also shown between stage III IBC and stage II/III non-IBC as well as between IBC and non-IBC with no active disease at transplantation. However, among the subgroup of stage III patients with no active disease at transplantation who were the "ideal" breast cancer patients for HDC with AHCT, the IBC patients had similar short term (1-year) outcomes but poorer long term (10-year) outcomes than that of non-IBC patients. Multivariate analysis also revealed that the stage III IBC patients regardless of the disease status at transplantation had poorer outcomes than did stage III non-IBC patients with a slightly inferior survival (hazard ratio for death $=1.16$ ) to that reported previously $(\mathrm{HR}=1.43)$ in non-transplant setting. ${ }^{3}$ Therefore the long term outcome of patients with IBC remained poor compared to that of patients with non-IBC even in the setting of transplantation.

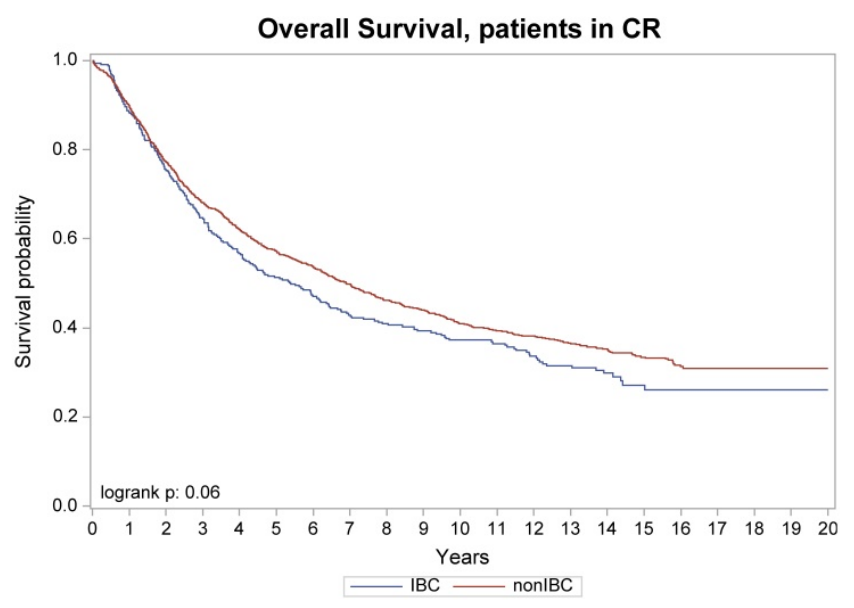

Figure 2. Overall survival, patients with no active diseases at transplant

Table 3. Univariate analysis

\begin{tabular}{|c|c|c|c|}
\hline & IBC (N=527), \% (95\% CI) & $\begin{array}{c}\text { Non-IBC }(\mathrm{N}=2,860), \% \\
(95 \% \mathrm{CI})\end{array}$ & $\mathrm{p}$ value \\
\hline 1-year TRM & $2(1-4)$ & $3(3-4)$ & 0.16 \\
\hline $\begin{array}{l}\text { 1-year } \\
\text { relapse/progression }\end{array}$ & $39(35-43)$ & $38(36-40)$ & 0.79 \\
\hline $\begin{array}{l}\text { 10-year } \\
\text { relapse/progression }\end{array}$ & $67(63-71)$ & $69(68-71)$ & 0.36 \\
\hline 1-year PFS & $59(54-63)$ & $58(57-60)$ & 0.86 \\
\hline 10-year PFS & $27(23-31)$ & $24(22-26)$ & 0.21 \\
\hline 1-year OS & $82(79-85)$ & $80(79-82)$ & 0.41 \\
\hline \multirow[t]{2}{*}{ 10-year OS } & $31(27-35)$ & $28(26-30)$ & 0.16 \\
\hline & $\begin{array}{l}\text { Stage III IBC }(\mathrm{N}=442), \% \\
(95 \% \mathrm{CI})\end{array}$ & $\begin{array}{l}\text { Stage II/III non-IBC } \\
(\mathrm{N}=2,302), \%(95 \% \mathrm{CI})\end{array}$ & p value \\
\hline 1-year TRM & $2(1-4)$ & $3(3-4)$ & 0.15 \\
\hline $\begin{array}{l}\text { 1-year } \\
\text { relapse/progression }\end{array}$ & $36(31-40)$ & $36(34-38)$ & 0.90 \\
\hline $\begin{array}{l}\text { 10-year } \\
\text { relapse/progression }\end{array}$ & $65(61-70)$ & $66(64-68)$ & 0.88 \\
\hline 1-year PFS & $62(57-67)$ & $61(59-63)$ & 0.57 \\
\hline 10-year PFS & $29(24-33)$ & $27(25-29)$ & 0.58 \\
\hline 1-year OS & $83(80-87)$ & $82(81-84)$ & 0.59 \\
\hline \multirow[t]{2}{*}{10 -year OS } & $32(28-37)$ & $31(29-33)$ & 0.74 \\
\hline & $\begin{array}{l}\text { Stage III IBC at CR } \\
(\mathrm{N}=304), \%(95 \% \mathrm{CI})\end{array}$ & $\begin{array}{l}\text { Stage II/III non-IBC at } \\
\text { CR }(\mathrm{N}=417), \%(95 \% \\
\text { CI) }\end{array}$ & p value \\
\hline 1-year TRM & $1(0-3)$ & $4(2-6)$ & 0.03 \\
\hline $\begin{array}{l}\text { 1-year } \\
\text { relapse/progression }\end{array}$ & $26(21-31)$ & $18(14-22)$ & 0.01 \\
\hline $\begin{array}{l}\text { 10-year } \\
\text { relapse/progression }\end{array}$ & $60(54-66)$ & $50(45-55)$ & 0.01 \\
\hline 1-year PFS & $72(67-77)$ & $78(74-82)$ & 0.09 \\
\hline 10-year PFS & $34(28-40)$ & $42(37-47)$ & 0.05 \\
\hline 1-year OS & $88(85-92)$ & $90(87-93)$ & 0.47 \\
\hline 10-year OS & $37(32-43)$ & $45(41-50)$ & 0.03 \\
\hline
\end{tabular}




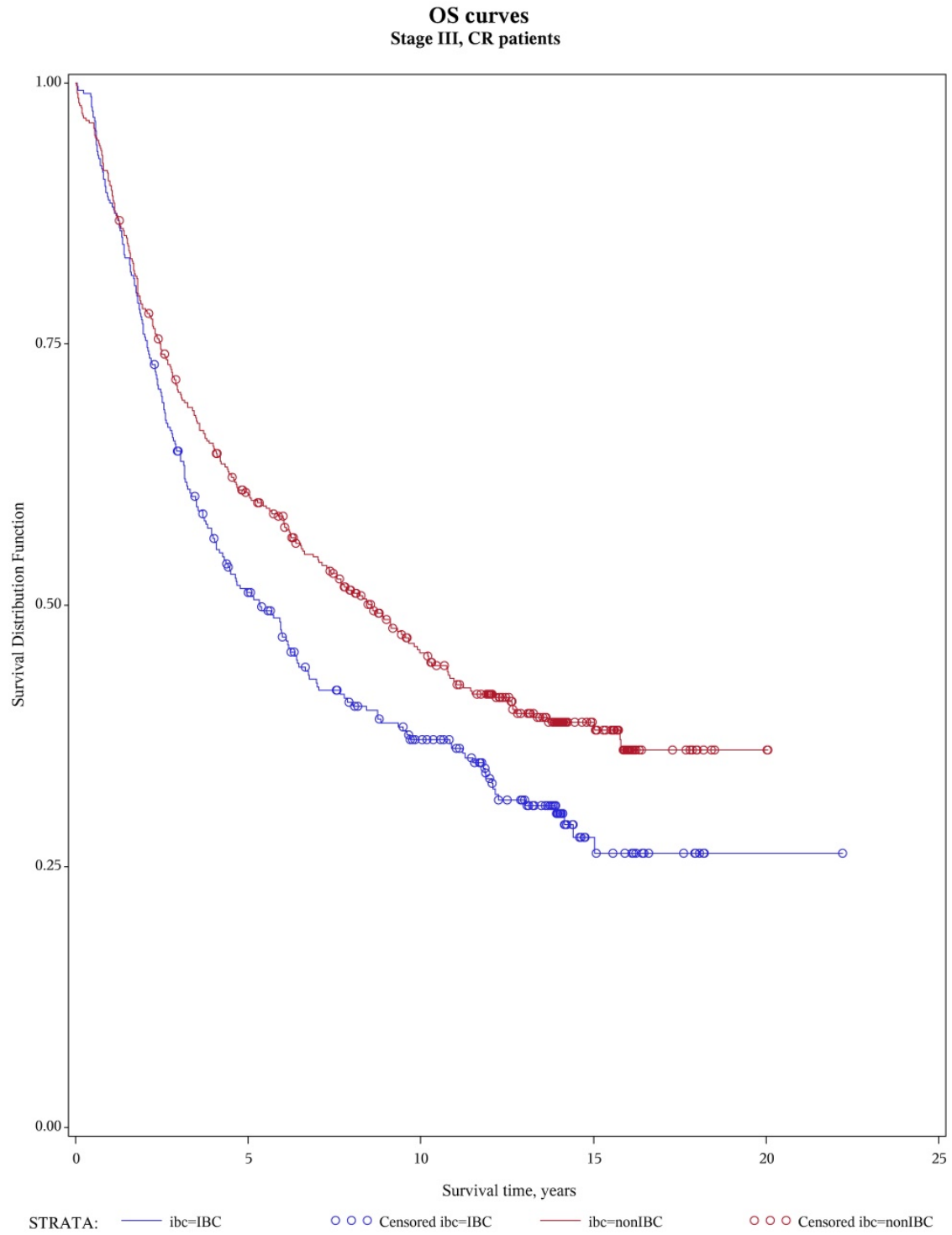

Figure 3. Overall survival, patients with stage III and no active diseases at transplant

Table 4. Multivariate analysis

\begin{tabular}{|c|c|c|c|c|c|c|}
\hline Factor/level & PFS/HR (95\% CI) & $\mathrm{p}$ value & OS, HR (95\% CI) & $p$ value & Relapse/ Progression & $\mathrm{p}$ value \\
\hline \multicolumn{7}{|l|}{ IBC } \\
\hline Stage IV & 1.00 & & 1.00 & & 1.00 & \\
\hline Stage III & $0.71(0.54-0.93)$ & 0.012 & $0.83(0.63-1.08)$ & 0.1611 & 0.68 & 0.0084 \\
\hline \multicolumn{7}{|l|}{ Non-IBC } \\
\hline Stage IV & 1.00 & & 1.00 & & 1.00 & \\
\hline Stage III & $0.93(0.83-1.04)$ & 0.196 & $0.90(0.8-1.00)$ & 0.0583 & $0.96(0.85-1.08)$ & 0.4999 \\
\hline Stage II & $0.65(0.58-0.72)$ & $<0.0001$ & $0.60(0.54-0.67)$ & $<0.0001$ & $0.62(0.55-0.70)$ & $<0.0001$ \\
\hline \multicolumn{7}{|l|}{ Stage III } \\
\hline Non-IBC & 1.00 & & 1.00 & & 1.00 & \\
\hline IBC & $1.17(1.01-1.36)$ & 0.0339 & $1.16(1.00-1.34)$ & 0.0459 & $1.24(1.06-1.45)$ & 0.0082 \\
\hline \multicolumn{7}{|l|}{ Stage IV } \\
\hline Non-IBC & 1.00 & & 1.00 & & 1.00 & \\
\hline IBC & $1.15(0.89-1.5)$ & 0.2924 & $0.94(0.73-1.22)$ & 0.6453 & $1.17(0.89-1.53)$ & 0.2696 \\
\hline Age, overall & & $<0.0001$ & & 0.0315 & & 0.0088 \\
\hline $20-34$ & 1.00 & & 1.00 & & 1.00 & \\
\hline $35-49$ & $0.82(0.71-0.94)$ & 0.0041 & $0.84(0.73-0.97)$ & 0.0141 & $0.81(0.70-0.93)$ & 0.0035 \\
\hline$\geq 50$ & $0.87(0.74-1.02)$ & 0.0923 & $0.91(0.78-1.07)$ & 0.2569 & $0.87(0.75-1.01)$ & 0.0752 \\
\hline Disease status, overall & & $<0.0001$ & & $<0.0001$ & & $<0.0001$ \\
\hline Complete response & 1.00 & & 1.00 & & 1.00 & \\
\hline Partial response & $1.78(1.59-1.99)$ & $<0.0001$ & $1.66(1.49-1.85)$ & $<0.0001$ & $1.85(1.65-2.08)$ & $<0.0001$ \\
\hline
\end{tabular}




\begin{tabular}{|c|c|c|c|c|c|c|}
\hline Stable disease & $1.87(1.62-2.17)$ & $<0.0001$ & $1.70(1.47-1.96)$ & $<0.0001$ & $1.96(1.68-2.28)$ & $<0.0001$ \\
\hline Progressive disease & $2.25(1.84-2.74)$ & $<0.0001$ & $2.21(1.82-2.68)$ & $<0.0001$ & $2.27(1.84-2.79)$ & $<0.0001$ \\
\hline Missing & $1.63(1.41-1.88)$ & $<0.0001$ & $1.48(1.28-1.7)$ & $<0.0001$ & $1.84(1.64-2.07)$ & $<0.0001$ \\
\hline Hormonal receptor status, overall & & $<0.0001$ & & $<0.0001$ & & $<0.0001$ \\
\hline Negative & 1.00 & & 1.00 & & 1.00 & \\
\hline Others & $0.82(0.74-0.9)$ & $<0.0001$ & $0.79(0.72-0.87)$ & $<0.0001$ & $0.79(0.71-0.87)$ & $<0.0001$ \\
\hline Missing & $0.92(0.83-1.03)$ & 0.136 & $0.96(0.86-1.06)$ & $<0.0001$ & $0.90(0.81-1.01)$ & 0.0685 \\
\hline Time from diagnosis to transplant, months, overall & & $<0.0001$ & & $<0.0001$ & & $<0.0001$ \\
\hline$\leq 6$ & 1.00 & & 1.00 & & 1.00 & \\
\hline $6-12$ & $1.19(1.06-1.33)$ & 0.0029 & $1.20(1.07-1.35)$ & 0.0016 & $1.19(1.05-1.35)$ & 0.0055 \\
\hline$\geq 12$ & $2.74(2.45-3.06)$ & $<0.0001$ & $2.57(2.30-2.87)$ & $<0.0001$ & $2.93(2.6-3.29)$ & $<0.0001$ \\
\hline
\end{tabular}

Our study is unique in terms of the numbers of patients and the duration of follow up. In the setting of HDC with AHCT the current analysis represents one of the largest numbers of breast cancer patients (more than 3,000 IBC and non-IBC patients together) and the longest follow up (more than 10 years). Given the long follow up, the nature of registry data and loss of interest in transplant treatment modality for breast cancer, there are limitations. With the concern of missing or unknown data, we also looked at 1-year short term outcomes since patients underwent HDC with AHCT would have had more complete follow up within the first year post-transplant. Similarly, data that are routinely obtained such as the HER2 receptor information were not collected in the era during which these transplants were performed. Since patients were contributed by numerous different transplant centers in the world, standard treatments given to the patient before transplant varied. Only $58 \%$ of patients with IBC and $10 \%$ of patients with non-IBC received neoadjuvant chemotherapy which was much less than the current standard of care for patients with IBC and for patients with locally advanced non-IBC. Nevertheless, our study suggests similar overall poor outcome of IBC patients who underwent HDC with AHCT compared with that of non-IBC patients. For stage III patients who underwent HDC with AHCT in the absence of active disease at transplant, our study confirmed the similar short term and the worse long term outcomes of IBC patients compared with non-IBC. The smaller HR for mortality of 1.16 compared to the previously reported HR of 1.43 in non-transplant setting may suggest that the potential benefit of HDC with AHCT is in short term disease control but not in long term disease eradication.

With 14 years of median follow up, the incidence of second primary malignancy was low, with the caveat of incomplete follow up mentioned earlier $(2,423$ patients were excluded due to $<80 \%$ follow-up completeness index at 10 years). In both groups, the chance of developing secondary malignancy after HDC was less than 3\%. The TRM from the transplant procedure was low at 2 and $3 \%$ in both the groups and the TRM from the second malignancy was also very low in both groups ( $1 \%$ each). None of the second malignancy was breast cancer. We are thereby able to conclude that the procedure of HDC with AHCT in breast cancer patients has very low risk of treatment-related mortality.

The role of HDC with AHCT in invasive breast cancer has long been debated. Since the late 1990s, a total of 15 randomized phase III trials of HDC with AHCT in high-risk primary breast cancer ${ }^{19-33}$ and 8 randomized phase III trials in metastatic breast cancer $^{34-41}$ have been described. In 2011, Berry et al. reported the first meta-analysis using individual data from all 15 trials in high-risk primary breast cancer ${ }^{42}$ and 6 of the 8 trials in metastatic breast cancer. ${ }^{43}$ In high-risk primary breast cancer setting, the analysis showed a significant benefit of HDC with AHCT in relapse-free survival with a HR of $0.87(p<0.001)$ but not in OS (HR of $0.94, p=0.13$ ). In metastatic breast cancer setting, the analysis showed a significant benefit in PFS with a HR of $0.76(p<0.001)$ but not in OS (HR of $0.89, p=0.13$ ). These findings also suggest that the potential benefit of HDC with AHCT is in slowing down the progression of disease. Subgroup analysis in both settings failed to show a benefit in any particular subpopulation. However, with the rarity of IBC, not many cases were included in the above randomized phase III trials. Some of the IBC cases were included in the locally advanced breast cancer group including non-inflammatory stage III breast cancer during the survival analysis. Therefore those randomized phase III trials did not particularly address the role of HDC with AHCT in IBC.

There has only been one randomized phase III study for patients with IBC who underwent HDC with AHST, which was the PEGASE 07 trial. ${ }^{44}$ However this trial did not evaluate the impact of transplant in IBC, but instead, it studied the use of adjuvant chemotherapy after AHCT in IBC. In this trial, all patients received 4 cycles of high-dose cyclophosphamide and epirubicin with the hematopoietic cells collected after the cycle 1 and re-infused after cycle 2, 3 and 4 upon enrollment. Then patients proceeded to locoregional therapy of primary surgery and radiation therapy. After the locoregional therapy, patients were randomized to 
either observation with no chemotherapy or another 4 cycles of adjuvant chemotherapy of docetaxel and 5-fluorouracil. The primary endpoint was disease-free survival. With a median follow up of 60 months and a total of 174 patients (87 in each arm), the 5-year disease-free survival for patients received no adjuvant chemotherapy and received adjuvant chemotherapy were $55 \%$ and $55.5 \%$ respectively (HR of $0.94, p=$ 0.81 ). The 5-year OS for patients received no adjuvant chemotherapy and received adjuvant chemotherapy were $70.2 \%$ and $70 \%$ respectively ( $\mathrm{HR}$ of $0.93, p=$ $0.81) .45$

Since the introduction of multidisciplinary approach especially the use of systemic cytotoxic chemotherapy as early as possible in the course of IBC management, there has not been any other major breakthrough in the treatment of IBC except in HER2 positive IBC. IBC is more likely to be HER2 positive than non-IBC. Literatures suggested about $35 \%$ of IBC overexpressed HER2. ${ }^{46}$, 47 The more favorable outcome of HER2 positive IBC is attributed to the effective therapy with adding trastuzumab to the chemotherapy. However, the outcome of HER2 negative IBC remains poor. Our study cannot support the use of HDC with AHCT in IBC outside of context of a clinical trial. IBC remains as one of the invasive breast cancers with poor prognosis. Pre-clinical research and well-designed clinical trials are needed to test the efficacy of new treatment modalities in IBC based on the pathobiology of the disease.

\section{Competing Interests}

The authors have declared that no competing interest exists.

\section{References}

1. Hance KW, Anderson WF, Devesa SS, Young HA, Levine PH. Trends in inflammatory breast carcinoma incidence and survival: the surveillance, epidemiology, and end results program at the National Cancer Institute. Journal of the National Cancer Institute 2005; 97(13): 966-75.

2. Ueno NT, Buzdar AU, Singletary SE, Ames FC, McNeese MD, Holmes FA et al. Combined-modality treatment of inflammatory breast carcinoma: twenty years of experience at M. D. Anderson Cancer Center. Cancer chemotherapy and pharmacology 1997; 40(4): 321-9.

3. Dawood S, Ueno NT, Valero V, Woodward WA, Buchholz TA, Hortobagyi GN et al. Differences in survival among women with stage III inflammatory and noninflammatory locally advanced breast cancer appear early: a large population-based study. Cancer 2011; 117(9): 1819-26.

4. Ayash LJ, Elias A, Ibrahim J, Schwartz G, Wheeler C, Reich E et al. High-dose multimodality therapy with autologous stem-cell support for stage IIIB breast carcinoma. Journal of clinical oncology : official journal of the American Society of Clinical Oncology 1998; 16(3): 1000-7.

5. Somlo G, Doroshow JH, Forman SJ, Odom-Maryon T, Lee J, Chow W et al. High-dose chemotherapy and stem-cell rescue in the treatment of high-risk breast cancer: prognostic indicators of progression-free and overall survival. Journal of clinical oncology : official journal of the American Society of Clinical Oncology 1997; 15(8): 2882-93.

6. Cheng YC, Rondon G, Yang Y, Smith TL, Gajewski JL, Donato ML et al. The use of high-dose cyclophosphamide, carmustine, and thiotepa plus autologous hematopoietic stem cell transplantation as consolidation therapy for high-risk primary breast cancer after primary surgery or neoadjuvant chemotherapy. Biology of blood and marrow transplantation : journal of the American Society for Blood and Marrow Transplantation 2004; 10(11): 794-804.

7. Viens P, Palangie T, Janvier M, Fabbro M, Roche H, Delozier T et al. First-line high-dose sequential chemotherapy with rG-CSF and repeated blood stem cell transplantation in untreated inflammatory breast cancer: toxicity and response (PEGASE 02 trial). British journal of cancer 1999; 81(3): 449-56.

8. Viens P, Penault-Llorca F, Jacquemier J, Gravis G, Cowen D, Bertucci F et al. High-dose chemotherapy and haematopoietic stem cell transplantation for inflammatory breast cancer: pathologic response and outcome. Bone marrow transplantation 1998; 21(3): 249-54.

9. Dazzi C, Cariello A, Rosti G, Tienghi A, Molino A, Sabbatini R et al. Neoadjuvant high dose chemotherapy plus peripheral blood progenitor cells in inflammatory breast cancer: a multicenter phase II pilot study. Haematologica 2001; 86(5): 523-9.

10. Palangie T PP, Roche $\mathrm{H}$, et al. Five year update of sequential high dose doxorubicin, cyclophosphamide and docetaxel in inflammatory breast cancer: PEGASE 05 trial on behalf of FNLCC. Proc Am Clin Oncol 2006; 24.

11. Cagnoni PJ, Nieto Y, Shpall EJ, Bearman SI, Baron AE, Ross M et al. High-dose chemotherapy with autologous hematopoietic progenitor-cell support as part of combined modality therapy in patients with inflammatory breast cancer. Journal of clinical oncology : official journal of the American Society of Clinical Oncology 1998; 16(5): 1661-8.

12. Schwartzberg L, Weaver C, Lewkow L, McAneny B, Zhen B, Birch R et al. High-dose chemotherapy with peripheral blood stem cell support for stage IIIB inflammatory carcinoma of the breast. Bone marrow transplantation 1999; 24(9): 981-7.

13. Adkins D, Brown R, Trinkaus K, Maziarz R, Luedke S, Freytes C et al. Outcomes of high-dose chemotherapy and autologous stem-cell transplantation in stage IIIB inflammatory breast cancer. Journal of clinical oncology : official journal of the American Society of Clinical Oncology 1999; 17(7): 2006-14.

14. Arun B, Slack R, Gehan E, Spitzer T, Meehan KR. Survival after autologous hematopoietic stem cell transplantation for patients with inflammatory breast carcinoma. Cancer 1999; 85(1): 93-9.

15. Yalamanchili K, Lalmuanpuii J, Waheed F, Farjami S, Kancherla R, Qureshi Z et al. High-dose chemotherapy with autologous stem cell rescue in stage IIIB inflammatory breast cancer. Anticancer research 2008; 28(5B): 3139-42.

16. Sportes C, Steinberg SM, Liewehr DJ, Gea-Banacloche J, Danforth DN, Avila $\mathrm{DN}$ et al. Strategies to improve long-term outcome in stage IIIB inflammatory breast cancer: multimodality treatment including dose-intensive induction and high-dose chemotherapy. Biology of blood and marrow transplantation journal of the American Society for Blood and Marrow Transplantation 2009; 15(8): 963-70.

17. Antman KH, Rowlings PA, Vaughan WP, Pelz CJ, Fay JW, Fields KK et al. High-dose chemotherapy with autologous hematopoietic stem-cell support for breast cancer in North America. Journal of clinical oncology : official journal of the American Society of Clinical Oncology 1997; 15(5): 1870-9.

18. Pedrazzoli P, Ferrante P, Kulekci A, Schiavo R, De Giorgi U, Carminati O et al. Autologous hematopoietic stem cell transplantation for breast cancer in Europe: critical evaluation of data from the European Group for Blood and Marrow Transplantation (EBMT) Registry 1990-1999. Bone marrow transplantation 2003; 32(5): 489-94.

19. Wilking N, Lidbrink E, Wiklund T, Erikstein B, Lindman H, Malmstrom P et al. Long-term follow-up of the SBG 9401 study comparing tailored FEC-based therapy versus marrow-supported high-dose therapy. Annals of oncology : official journal of the European Society for Medical Oncology / ESMO 2007; 18(4): 694-700.

20. Hanrahan EO, Broglio K, Frye D, Buzdar AU, Theriault RL, Valero V et al. Randomized trial of high-dose chemotherapy and autologous hematopoietic stem cell support for high-risk primary breast carcinoma: follow-up at 12 years. Cancer 2006; 106(11): 2327-36.

21. Roche HH PP, Meyer $\mathrm{N}$ et al. Adjuvant high-dose chemotherapy (HDC) improves early outcome for high risk $(\mathrm{N}>7)$ breast cancer patients: the PEGASE 01 trial. In: Pro Am Soc Clin Oncol, 2001. p 26a.

22. Gianni A BG. Updated 12-year results of a randomized clinical trial comparing standard-dose versus high-dose myeloablative chemotherapyin the adjuvant treatment of breast cancer with more than 3positive nodes (N+). . Proc Am Clin Oncol 2007; 25.

23. Schrama JG, Faneyte IF, Schornagel JH, Baars JW, Peterse JL, van de Vijver MJ et al. Randomized trial of high-dose chemotherapy and hematopoietic progenitor-cell support in operable breast cancer with extensive lymph node involvement: final analysis with 7 years of follow-up. Annals of oncology : official journal of the European Society for Medical Oncology / ESMO 2002; 13(5): 689-98.

24. Rodenhuis S, Bontenbal M, Beex LV, Wagstaff J, Richel DJ, Nooij MA et al. High-dose chemotherapy with hematopoietic stem-cell rescue for high-risk breast cancer. The New England journal of medicine 2003; 349(1): 7-16.

25. Tallman MS, Gray R, Robert NJ, LeMaistre CF, Osborne CK, Vaughan WP et al. Conventional adjuvant chemotherapy with or without high-dose chemotherapy and autologous stem-cell transplantation in high-risk breast cancer. The New England journal of medicine 2003; 349(1): 17-26.

26. Leonard RC, Lind M, Twelves C, Coleman R, van Belle S, Wilson C et al. Conventional adjuvant chemotherapy versus single-cycle, autograft-supported, high-dose, late-intensification chemotherapy in high-risk breast cancer patients: a randomized trial. Journal of the National Cancer Institute 2004; 96(14): 1076-83

27. Zander AR, Schmoor C, Kroger N, Kruger W, Mobus V, Frickhofen N et al. Randomized trial of high-dose adjuvant chemotherapy with autologous hematopoietic stem-cell support versus standard-dose chemotherapy in breast cancer patients with 10 or more positive lymph nodes: overall survival after 6 
years of follow-up. Annals of oncology : official journal of the European Society for Medical Oncology / ESMO 2008; 19(6): 1082-9.

28. Coombes RC, Howell A, Emson M, Peckitt C, Gallagher C, Bengala C et al. High dose chemotherapy and autologous stem cell transplantation as adjuvant therapy for primary breast cancer patients with four or more lymph nodes involved: long-term results of an international randomised trial. Annals of oncology : official journal of the European Society for Medical Oncology / ESMO 2005; 16(5): 726-34

29. Nitz UA, Mohrmann S, Fischer J, Lindemann W, Berdel WE, Jackisch C et al. Comparison of rapidly cycled tandem high-dose chemotherapy plus peripheral-blood stem-cell support versus dose-dense conventional chemotherapy for adjuvant treatment of high-risk breast cancer: results of a multicentre phase III trial. Lancet 2005; 366(9501): 1935-44.

30. Peters WP, Rosner GL, Vredenburgh JJ, Shpall EJ, Crump M, Richardson PG et al. Prospective, randomized comparison of high-dose chemotherapy with stem-cell support versus intermediate-dose chemotherapy after surgery and adjuvant chemotherapy in women with high-risk primary breast cancer: a report of CALGB 9082, SWOG 9114, and NCIC MA-13. Journal of clinical oncology : official journal of the American Society of Clinical Oncology 2005; 23(10): 2191-200.

31. International Breast Cancer Study G, Basser RL, O'Neill A, Martinelli G, Green $\mathrm{MD}$, Peccatori $\mathrm{F}$ et al. Multicycle dose-intensive chemotherapy for women with high-risk primary breast cancer: results of International Breast Cancer Study Group Trial 15-95. Journal of clinical oncology : official journal of the American Society of Clinical Oncology 2006; 24(3): 370-8.

32. Moore HC, Green SJ, Gralow JR, Bearman SI, Lew D, Barlow WE et al. Intensive dose-dense compared with high-dose adjuvant chemotherapy for high-risk operable breast cancer: Southwest Oncology Group/Intergroup study 9623. Journal of clinical oncology : official journal of the American Society of Clinical Oncology 2007; 25(13): 1677-82.

33. Tokuda Y, Tajima T, Narabayashi M, Takeyama K, Watanabe T, Fukutomi T et al. Phase III study to evaluate the use of high-dose chemotherapy as consolidation of treatment for high-risk postoperative breast cancer: Japan Clinical Oncology Group study, JCOG 9208. Cancer science 2008; 99(1): 145-51.

34. Stadtmauer EA, O'Neill A, Goldstein LJ, Crilley PA, Mangan KF, Ingle JN et al. Conventional-dose chemotherapy compared with high-dose chemotherapy plus autologous hematopoietic stem-cell transplantation for metastatic breast cancer. Philadelphia Bone Marrow Transplant Group. The New England journal of medicine 2000; 342(15): 1069-76.

35. Crown J PL, Lind M et al. . Superioity of tandem high-dose chemotherapy (HDC) versus optimized conventionally-dose chemotherapy (CDC) in patients (pts) with metastatic breast cancer (MBC): the International Breast Cancer Dose Intensity Study (IBDIS 1). Proc Am Clin Oncol 2003; 22.

36. Schmid P, Schippinger W, Nitsch T, Huebner G, Heilmann V, Schultze W et al. Up-front tandem high-dose chemotherapy compared with standard chemotherapy with doxorubicin and paclitaxel in metastatic breast cancer: results of a randomized trial. Journal of clinical oncology : official journal of the American Society of Clinical Oncology 2005; 23(3): 432-40.

37. Lotz JP, Cure H, Janvier M, Asselain B, Morvan F, Legros M et al. High-dose chemotherapy with haematopoietic stem cell transplantation for metastatic breast cancer patients: final results of the French multicentric randomised CMA/PEGASE 04 protocol. European journal of cancer 2005; 41(1): 71-80.

38. Vredenburgh JJ, Coniglio D, Broadwater G, Jones RB, Ross M, Shpall EJ et al. Consolidation with high-dose combination alkylating agents with bone marrow transplantation significantly improves disease-free survival in hormone-insensitive metastatic breast cancer in complete remission compared with intensive standard-dose chemotherapy alone. Biology of blood and marrow transplantation : journal of the American Society for Blood and Marrow Transplantation 2006; 12(2): 195-203.

39. Vredenburgh JJ, Madan B, Coniglio D, Ross M, Broadwater G, Niedzwiecki D et al. A randomized phase III comparative trial of immediate consolidation with high-dose chemotherapy and autologous peripheral blood progenitor cell support compared to observation with delayed consolidation in women with metastatic breast cancer and only bone metastases following intensive induction chemotherapy. Bone marrow transplantation 2006; 37(11): 1009-15.

40. Biron P, Durand M, Roche H, Delozier T, Battista C, Fargeot P et al. Pegase 03: a prospective randomized phase III trial of FEC with or without high-dose thiotepa, cyclophosphamide and autologous stem cell transplantation in first-line treatment of metastatic breast cancer. Bone marrow transplantation 2008; 41(6): 555-62.

41. Crump M, Gluck S, Tu D, Stewart D, Levine M, Kirkbride P et al. Randomized trial of high-dose chemotherapy with autologous peripheral-blood stem-cell support compared with standard-dose chemotherapy in women with metastatic breast cancer: NCIC MA.16. Journal of clinical oncology : official journal of the American Society of Clinical Oncology 2008; 26(1): 37-43.

42. Berry DA, Ueno NT, Johnson MM, Lei X, Caputo J, Rodenhuis $S$ et al. High-dose chemotherapy with autologous stem-cell support as adjuvant therapy in breast cancer: overview of 15 randomized trials. Journal of clinical oncology : official journal of the American Society of Clinical Oncology 2011; 29(24): 3214-23.

43. Berry DA, Ueno NT, Johnson MM, Lei X, Caputo J, Smith DA et al. High-dose chemotherapy with autologous hematopoietic stem-cell transplantation in metastatic breast cancer: overview of six randomized trials. Journal of clinical oncology : official journal of the American Society of Clinical Oncology 2011; 29(24): 3224-31.
44. Roche H, Viens P, Biron P, Lotz JP, Asselain B, Group P. High-dose chemotherapy for breast cancer: the French PEGASE experience. Cancer control : journal of the Moffitt Cancer Center 2003; 10(1): 42-7.

45. Goncalves A, Pierga JY, Ferrero JM, Mouret-Reynier MA, Bachelot T, Delva R et al. UNICANCER-PEGASE 07 study: a randomized phase III trial evaluating postoperative docetaxel-5FU regimen after neoadjuvant dose-intense chemotherapy for treatment of inflammatory breast cancer. Annals of oncology: official journal of the European Society for Medical Oncology / ESMO 2015; 26(8): 1692-7.

46. Turpin E, Bieche I, Bertheau P, Plassa LF, Lerebours F, de Roquancourt A et al. Increased incidence of ERBB2 overexpression and TP53 mutation in inflammatory breast cancer. Oncogene 2002; 21(49): 7593-7.

47. Brouwers B, Paridaens R, Lobelle JP, Hendrickx W, Smeets A, Neven P et al. Clinicopathological features of inflammatory versus noninflammatory locally advanced nonmetastatic breast cancer. Tumour biology : the journal of the International Society for Oncodevelopmental Biology and Medicine 2008; 29(4): 211-6. 